\title{
Innovative Environmental Strategy for Sustainable Development
}

\author{
Grygorii Kaletnik ${ }^{1}$, Svitlana Lutkovska ${ }^{2}$
}

\begin{abstract}
This article investigates the development of an innovative strategy for environmentally sustainable development. The breakthrough strategy has been found to be an activity-based structure and system of activities to accelerate growth. It has been found out that, in form and substance, all practical business development strategies depend on specific internal and external circumstances. It is proved that when developing breakthrough strategies for socio-economic development of a country, it is necessary to be guided by certain methodical techniques or rules, namely: scientific and applied justification; identifying and progressively improving an attractive value proposition; development and continuous improvement of the business model; drawing up and implementing an action plan; forming the focus of all participants in the breakthrough strategy on the achievement of strategic goals. The main products of the breakthrough strategy are found to be the organizational mission, value proposition, business model and set of projects and programs that form the breakthrough strategy cycle [2, 4]. It is found that there are different types of breakthrough strategies, among them the following: 1) storming strategy; 2) lagging behind in leaders; 3) expansion of horizons; 4) change of form [3]. Breakthrough strategies in the industry include the introduction of modern innovative industrial technologies on the basis of support for the development of hightech industries (increasing production of domestic aviation and space technology, instrumentation, electronic technology, nanotechnology, medical technology), harnessing the potential of Ukraine to expand medium-tech production automotive, newest rolling stock and other railway equipment), Stim fostering the creation of new innovation development poles (creation of innovation clusters in the regions of Ukraine)[4]. It is proved that sustainable environmental development is impossible without the formation and use of appropriate management potential, that is, the ability of managers is qualified to "launch" all other potentials. It has been determined that the goal of green economy development should be to achieve a higher level of well-being while simultaneously solving resourceecological and social problems.
\end{abstract}

Keywords: strategy, innovation, environmental security, sustainable development.

\section{Introduction.}

The transition of the Ukrainian economy to the market economic system has determined the relevance of technological upgrading of the economy and increasing the competitiveness of domestic enterprises, and therefore the use of foreign experience of transformation of the economic system and technology upgrade. The most significant

\footnotetext{
| ${ }^{1}$ Doctor of Economics, Professor, Academician of NAAS of Ukraine, Head of the Department of Administrative Management and Alternative Energy Sources, Vinnytsia National Agrarian University, Vinnitsia, Ukraine.

${ }^{2}$ Candidate of Pedagogical Sciences, Associate Professor, Vice-rector for scientific and pedagogical work, European integration and international activities, Associate Professor of the Department of Administrative Management and alternative energy sources Vinnytsia National Agrarian University, Vinnitsia, Ukraine.
} 
feature of this experience is the qualitative improvement of approaches to structural and technological development of the economy [13].

Today, measures aimed at the rational use of natural resources and the stabilization and rehabilitation of the environment do not have the desired effect. The main reasons for this are: lack of a unified integrated approach and coordination in solving these problems, insufficient financing of environmental protection measures, lack of a truly effective economic mechanism of environmental management, poor organizational management structure in this area. Excessive exploitation of certain types of natural resources, imperfection of forms and ways of their involvement in the reproductive process require revision of priorities of their use, elaboration of clear targets for the strategy in the field of nature management, scientific substantiation of actions and mechanisms for their achievement [11]. You can solve these problems by developing an effective breakthrough strategy in this area. It is this problem that determined the purpose of this study.

\section{Literature Review}

Recently, fundamental scientific researches have deepened, in which environmental and economic-ecological problems are the subject of particular attention of domestic and foreign scientists. In particular, the works are devoted to the development of these issues: Ivanyuti, K.V. Taranyuk, A.B. Kachinsky, B. V. Vitlinsky, G.M. Kaletnik, SV Kozlovsky, OV Dlugopolsky, OO Veklych, MV Golovanenko, SM Ilyashenko, OV Kozmenko, S.K. Kharichkova, ON Rusaka, OV Sadchenko, K.F. Frolova, OV Kharlamova, VM Shmandi and others [5, 7]. In addition, the current scientific literature and current regulations contain a large number of individual approaches to the description of environmental safety, but there is no comprehensive study on the development of a strategy for a breakthrough towards sustainable environmental development.

The purpose of the research is to develop an innovative strategy for environmentally sustainable development based on the use of modern scientific methods and approaches that are highly effective and put into practice in other related fields of research.

\section{Methodology}

In the process of research, the dialectical method of cognition was taken as the basis. Methods of economic analysis, which were used in the course of the study: abstract-logical method, providing theoretical generalizations, the formation of conclusions; statistical and economic method, in particular, comparison of quantitative and qualitative indicators; graphical - to reflect the analytical and statistical information and individual processes; mathematical modeling that allows you to analyze a managed system for the effects of external and internal control effects and to choose such management methods that will lead to an optimal change in system behavior. 


\section{Case studies}

A breakthrough strategy is an activity-based structure and system of activities to accelerate growth. It is a means by which executives can create and control the future based on a deliberate and innovative way of acting by individuals or entire teams seeking to achieve high growth and market leadership. In the context of business management, a breakthrough strategy is a systematic approach to forcibly withdrawing from a restrictive state or position. As a structured and purposeful approach to corporate change, as well as transformation of the market or industry, causing a dramatic improvement of the company and business prosperity, the strategy is a mechanism that connects all components of the organization, demonstrates the unity of goals, setting direction and creating acceleration, necessary for growth and positive change $[3,4]$.

In terms of form and substance, all practical business development strategies depend on specific internal and external circumstances. Experts have identified three common perspectives on breakthrough strategies used by companies with double-digit growth rates [8].

1. Absolutely perfect implementation of simple strategies, not their prettiness. Most successful companies showcase their simple, honest, and understandable value propositions - but the leader is the company that will support this offer with a wellestablished and clear business model.

2. A well thought out procedure for drawing up an engagement strategy. There are no standard techniques, templates, tools or technologies here, but fast-growing organizations prefer their own and unique ways of formulating a strategy. These include reviewing and adjusting strategy, business planning, formulating strategic goals and activities, and creating and monitoring strategic projects and programs. A distinctive feature of the breakthrough strategy development process is the clear alignment of the company's mission and global performance standards, as well as the process of acquiring and merging businesses, innovation and new product development, business growth, and information management.

3. Excellent knowledge of organizational aspects and dynamics of the firm industry, countries to create an effective strategy.

When developing breakthrough strategies for socio-economic development of the country should be guided by certain methodological techniques or rules:

- $\quad$ scientific and applied justification of the organizational mission of the state, which should be both internally and externally directed, based on realistic fulfillment of current opportunities, taking into account limitations and difficulties. The mission statement must take into account market, internal organization, external relations, and corporate culture;

- $\quad$ identifying and progressively improving an attractive value proposition targeting large, growing and profitable market segments. The task is to identify and try to conquer new niches in the market, taking into account all the driving forces that operate in the markets where the strategy object operates;

- development and continuous improvement of the business model that reflects the value proposition of the strategy subject. Along with the business model, a set of 
projects and programs are being developed aimed at implementing the business model of the organization for the effective implementation of the value proposition. Successful firms, industries, and territorial systems are capable not only of forming markets but also of creating organizations that can serve these markets. Along with creating the concept of a successful value proposition, you need to be able to implement it. To this end, it is important to ensure that the correct investments are made in the right quantities and to shape them in accordance with the requirements of the region's business model. As markets grow and evolve, requirements are constantly changing, and therefore, the renewal and expansion of organizational resources and capabilities is a continuous challenge. Structures, systems and processes must be consistent with the market, as is the amount and level of knowledge and ability of employees;

- drawing up and implementing an action plan to ensure effective investment in accordance with the mission of the organization. Breakthrough as a dynamic process involves simultaneous and constant change. Upgrading should cover all areas capabilities, capacities, distribution, products, personnel, policies, procedures, methods, systems, processes, markets, consumers, suppliers and partners - and linking all of these together is the most important task [12]. This task will be facilitated by detailed planning that takes into account all aspects of the business and the realization of opportunities. In this case, it is important to have full control over the situation and to connect the resources available to carry out the planned projects and programs important for the achievement of the strategic goals;

- $\quad$ shaping the focus of all participants in the breakthrough strategy on achieving the strategic goals. Successful executives must demonstrate all leadership capabilities that make them believe in the organization and do their best to prosper and succeed, even in critical situations. The imperative is to raise morale by building confidence in the strategy, focusing on the big future, developing healthy internal and external relations, maintaining the flexibility to change when the course is needed.

Continuity and consistency of goals are key to strategy implementation. Since no organization is able to control its external environment, and markets and competitors are constantly changing, adequate counterparts, regular and systematic implementation of changes and improvements, which are part of any effective strategy to create and improve value proposition, must be important components of the strategy. is central to the breakthrough strategy.

To develop a breakthrough strategy, it is necessary to use global strategies that are developed and implemented on the basis of global installations. The strategy of globalization allows to gain strategic advantage or to neutralize the advantage of competitors. For example, product or marketing applications developed for one market may be used in another market. Cost savings can be achieved through economies of scale due to the global nature of the market or access to cheap labor and raw materials. Even if the globalization strategy is not optimal for business, it is helpful to consider global realities when conducting environmental analysis. Knowledge of competitors, markets and trends in other countries enables the company to identify important opportunities, threats and strategic uncertainties. Of course, analyzing the global external environment is much more difficult because we have to consider different cultures, political risks and economic systems. 
The main products of the breakthrough strategy are organizational mission, value proposition, business model and set of projects and programs (Fig. 1) [10]. These products are the result of a specific strategic process. So strategic thinking is aimed at obtaining a real and valid position of the region, its future prospects. It requires critical and wide-ranging thinking, a high level of analysis of the market, industries and the environment, along with the willingness of the organization to compete successfully in the international and domestic arena.

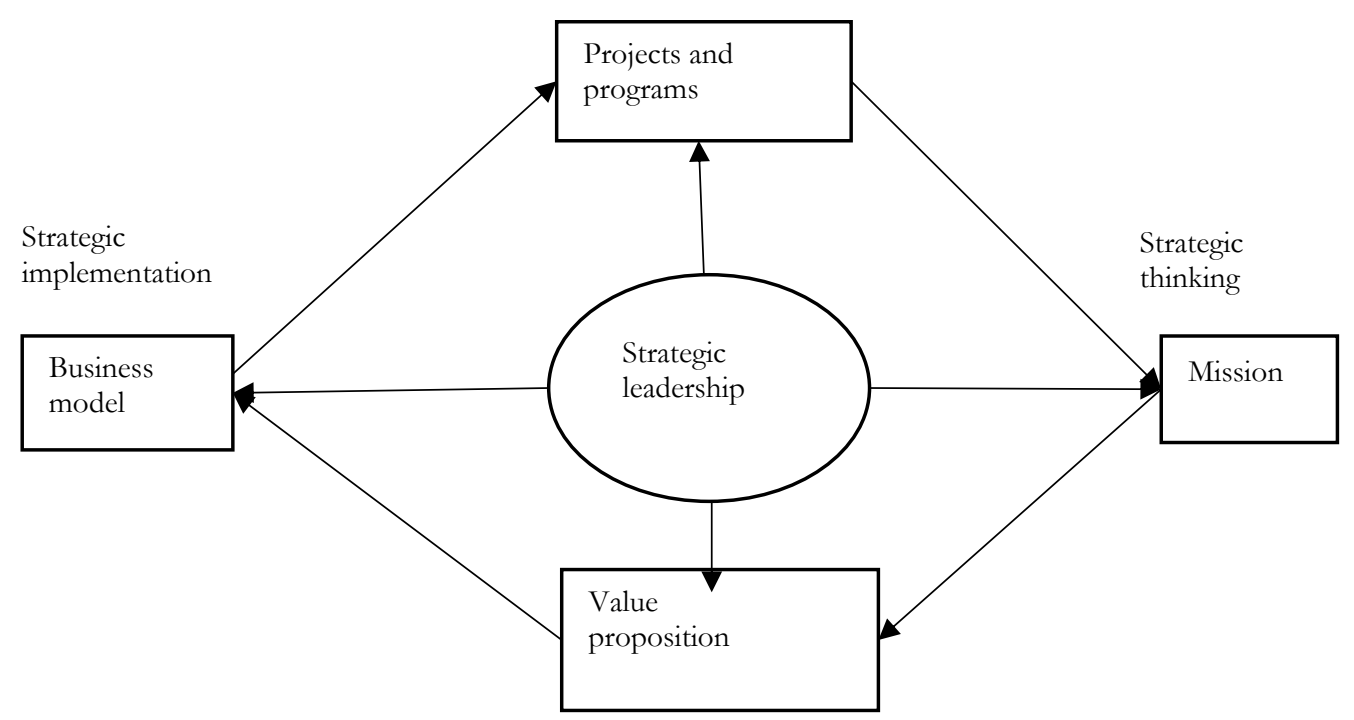

Figure 1: A cycle of breakthrough strategies

Source: developed based on [10]

There are different types of breakthrough strategies. Among them are [1, 4]:

1) a strategy of storming. In this case, a new and unknown company becomes a powerful market power in a few years. These are mostly new companies that are going to provide new services or launch new products;

2) lagging behind in leaders. This is a form of breakthrough when the organization, being in the shadows for a long time, begins to accelerate through new leadership and a new strategy, upgrading from lagging behind to leaders;

3) expanding horizons. This type of breakthrough is based on the rapid expansion of the organization in the market and its transformation from local or regional to a developed international;

4) change of form. This type of breakthrough is characterized by the radicalization of activities aimed not at the core activity, but at a new transformation of business as a result of becoming a completely different type of organization.

Breakthrough strategies in the industry include the introduction of modern innovative industrial technologies on the basis of support for the development of high-tech industries (increasing production of domestic aviation and space technology, instrumentation, electronic technology, nanotechnology, medical technology), harnessing the potential of Ukraine to expand medium-tech production automotive, newest rolling 
stock and other railway equipment), Stim fostering the creation of new innovation development poles (creation of innovation clusters in the regions of Ukraine) [4]. The main measures to support the development of high-tech industries are [4,13]:

- $\quad$ The development and implementation of state programs for the development of aviation, rocket-space, shipbuilding, defense, instrument-making, microelectronic industries in terms of financing research and development work aimed at strengthening the innovative component of the development of high-tech industries accepted priorities;

- $\quad$ the use of space technologies in the process of creation and production of hightech products for the needs of the domestic market and for export;

- technological modernization of enterprises, creation of basic scientificproduction and technological centers and development of critical technologies, the main of which are: special technologies for creation of rockets, spacecraft and terrestrial infrastructure with the use of new technical solutions; production technologies with a new level of quality and properties based on the use of the latest methods and means; new materials that ensure the quality and properties of products; special purpose fuel and energy technologies; ecology and safety of products, industries and facilities.

- information provision and creation of conditions for wide access for all specialists (students) to the up-to-date information on the advanced technologies and the latest inventions in the world and in Ukraine.

Using the potential of Ukraine to expand medium-tech industries includes [4]:

- $\quad$ Promoting the creation of leasing companies to support agricultural producers in the purchase of agricultural machinery;

- $\quad$ ensuring the financing of budget programs aimed at the development of secondary reserves of raw materials using the best available foreign and domestic technologies for the secondary use of raw materials and the reclamation of places of their storage;

- $\quad$ promoting the creation of a new generation of machinery and equipment for the agro-industrial complex, energy, transport and housing and communal services;

- scientific support for the creation of a competitive element base and components for the electronics industry, instrumentation, communications and telecommunications, including ultra-high frequency products and nano-physics and nanoelectronics;

- development of incentives for the formation of closed-loop macrotechnology in the basic industries, in particular in mechanical engineering for the agro-industrial complex, aviation, shipbuilding, defense-industrial complex, production of communication and telecommunications equipment, electrical equipment, household appliances;

- $\quad$ harmonization of the system of national standards in industry with international and European ones;

- $\quad$ promoting the development of biotechnologies, ceramics of a wide range of uses, super-rigid tool materials. 
Promoting the creation of new innovative poles of development and import substitution provides [14]:

- $\quad$ promoting the creation of a network of industrial clusters for the production of competitive products;

- promotion of projects focused on the development of breakthrough technologies;

- $\quad$ promoting the expansion of domestic production of household appliances.

A breakthrough strategy involves creation a competitive, sustainable, research and development sector with an optimal institutional structure; effective use of public funds allocated for financing scientific and scientific-technical activities; Ukraine's accession to the European and world scientific and technological space.

Strengthening the role of the state in ensuring technological breakthrough and modernization of production include $[1,12]$ :

- development of mechanisms of public-private partnership in realization of large perspective directions of innovative development;

- $\quad$ use of methodology of technological prediction for carrying out predictive researches of scientific and technical and innovative development and systematic use of the obtained results in carrying out program-targeted planning and financing;

- $\quad$ creation of financial institutions that ensure continuity of financing of business projects at all stages of the innovation cycle, redistribution of state funding to programs of support for innovative projects, which are at an early stage;

- $\quad$ ensuring the effective operation of a network of specialized non-banking innovative financial institutions, including by extending their rights to participate in the creation of corporate investment funds;

- further development of the network of innovative structures, including technopolis, technology parks, business incubators, innovation clusters, technology transfer centers;

- $\quad$ intensifying the development of venture business through the creation and further improvement of the existing regulatory framework, in particular as regards:

- expansion of sources of formation of financial resources of venture funds, namely at the expense of the funds of individual citizens, corporations, insurance companies, pension funds, other special funds, as well as the proceeds of venture capital from foreign sources;

- $\quad$ ensuring direct involvement of the state in the creation of extrabudgetary and venture funds;

- $\quad$ creation of a mechanism of insurance of venture investments;

- $\quad$ complete exemption of venture capital enterprises from payment of any taxes up to 5 years;

- $\quad$ application of preferential income tax to venture capital enterprises; tax rebates on private investment in venture funds and preferential loans to venture funds;

- $\quad$ promoting the establishment of branches of Ukrainian scientific-technological and innovative enterprises abroad, promotion of Ukrainian innovative products on world markets; 
- $\quad$ creation of databases of technologies and research, created at the expense of the state budget, as well as provided by interested private organizations and enterprises with access to databases via the Internet;

- Establishment of regional and sectoral centers for commercialization and transfer of technologies and innovations with the transition to the establishment of a national network of commercialization and transfer of technologies and innovations;

- introduction of mechanisms of advancement to the internal and external markets of technologies, inventions created at the expense of the state budget;

- development and adoption of amendments to the norms of the current legislation with the purpose of organizational, logistical and financial assistance to the implementation of the outsourcing mechanism of involvement of domestic research base and human resources in the creation, production and improvement of innovative product of the regional level.

Sustainable environmental development is possible based on the model proposed in [5]. Sustainable development is not possible without the formation and utilization of appropriate management potential, that is, the ability of managers to "launch" all other potentials. Management potential is the "core" of sustainable development, organically integrated with production, financial and intellectual innovation potentials, that is shown in Figure 2.

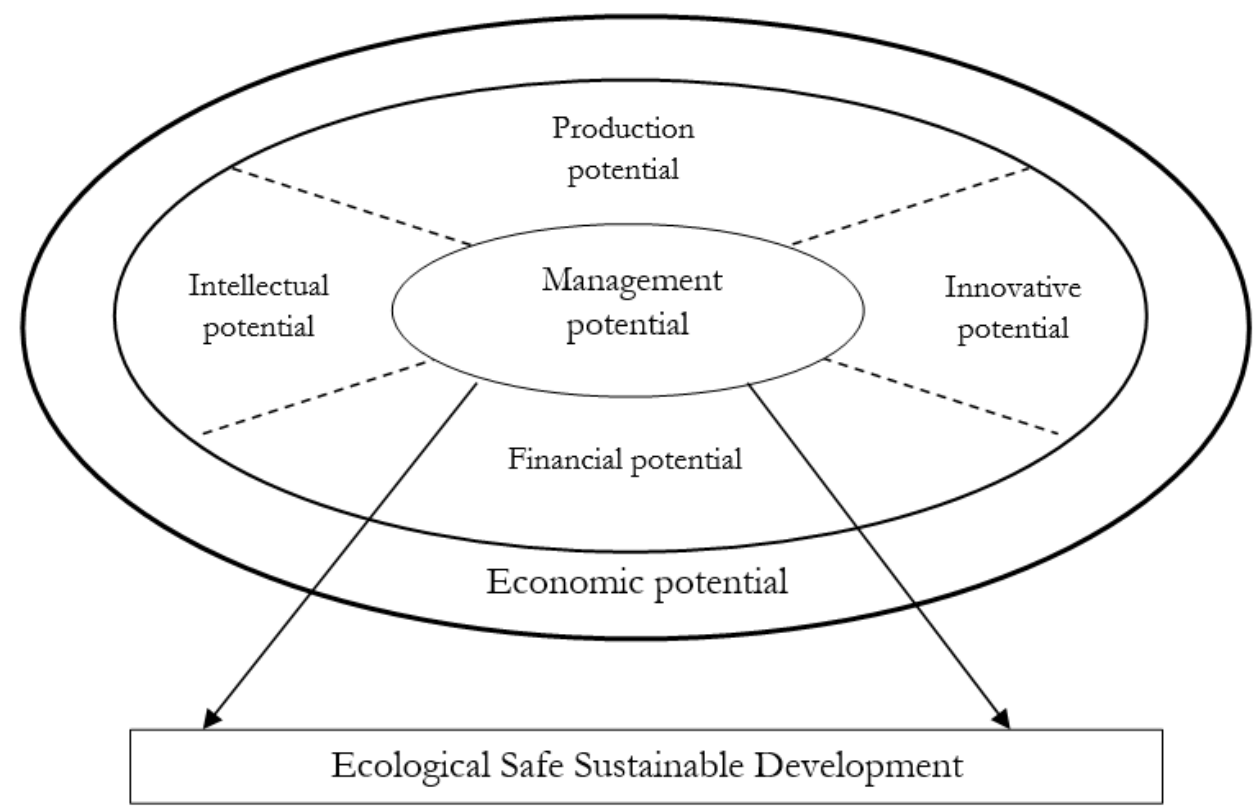

Figure 2: Components of environmentally sustainable development

Source: developed based on $[6,7]$

The above analysis provides convincing grounds for determining the following conditions for Ukraine's transition to a sustainable development model [12]: 
- environmentally friendly economic development, which should result in the achievement of a higher level of well-being while simultaneously addressing resource, environmental and social goals;

- the reproduction and rational use of all kinds of resources, the introduction of an effective system of environmental management and protection of the environment, the maintenance of ecological equilibrium, as a basis for environmental protection for present and future generations;

- the need for systematic ecological and economic restructuring of industry, agriculture, coordination of goals and measures for the development of industries and regions, individual enterprises, which are elements of the socio-ecological and economic system of the country;

- cooperation with international organizations on sustainable development and resolution of resource and environmental problems on the basis of innovative economic development, implementation of best practices and best scientific, technical and socioeconomic achievements;

- promoting the principles of social justice in society, overcoming social problems and stabilizing on this basis the demographic situation in the country, reducing the incidence and increasing the life expectancy of a person $[3,7]$.

\section{Discussion and Conclusions.}

World experience in technological breakthroughs shows that a country can increase its innovation level and become one of the most technologically advanced, usually in the stages of growth of the next technological system. It is in the period of change of technological structures and structural restructuring of the world economy, which occur at the beginning of the XXI century., It is necessary to create in the national economy competitive production of new technological structures that can strengthen the position of the state in the world market. This possibility is caused first of all by the fact that Ukraine lacks the production capacities of the fifth technological unit, and accordingly - the problem of the release of related capital and the lack of resistance of socio-economic institutions to structural restructuring of the economy on innovative grounds.

A selective structural and technological policy may be the most important instrument of the state in this process. The prospects for the dynamic growth of industrial production and the increase in exports of high-level goods are directly dependent on the pace of technological modernization of the economy. Only a move to higher standards of world experience can lead to progress in accelerating the competitiveness of the national economy.

Therefore, environmental policy in Ukraine requires a clear system of alternative conceptual decisions, which in the course of discussion in the society must be implemented through the legislatively regulated legal norms, organizational measures and executive actions of all state institutions regulating the development in the field of ecology and environmental protection. The first step in the functioning of the environmental management system is the formation of a scientifically sound and socially balanced, adequate environmental policy of the state. Such a policy is a specific 
organizational work of public authorities, based on a well-defined purpose and purpose, aimed at meeting the requirements of environmental legislation, focused on ensuring the right of citizens to environmentally safe living and development conditions [4].

\section{References:}

Amosha O.I., Antonyuk V.P., Zemlyakin A.I. (2007), Aktivizacia innivaciynoi dialnosty: organizaciynopravove ta socialne zabezpechinnia [Activation of innovative activity: organizational and legal and social security]. Donetsk, Ukraine.

Security of the regions of Ukraine and strategy of its guarantee in 2 volumes: T1. - Natural-technogenic (ecological) safety / [B. Danylyshyn, A. Stepanenko, O. Ralchuk and others]. - K.: Scientific Thought, 2008. - 392 p.

Ecological modernization in the system of natural-technogenic and ecological safety: [monograph] / [Stepanenko A.V., Obikhod G.A., Omelchenko A.A. etc.]; State Institution "Institute of Economics of Environmental Management and Sustainable Development of the National Academy of Sciences of Ukraine". - K .: State University of IEPSR NAS of Ukraine, 2016. - 435 p.

Innovation-investment and technological security of transformation of regional economic systems: monograph / M.A. Khvesik, A.V. Stepanenko, G.A. Obykhod etc. / for science. ed. Acad. NAAS of Ukraine MA Hvesika / State Institution «Institute of Economics of Environmental Management and Sustainable Development of National Academy of Sciences of Ukraine». - K .: Scientific-Production Enterprise "Publishing House" Scientific Thought "of NAS of Ukraine", 2013. - 487 p.

Kaletnik G. M., Zabolotnyi, G. M. Kozlovskyi S. V. (2011), "Innovative models of strategic management economic potential within contemporary economic systems", Actual Problems of Economics, vol, 4(118), pp. 3-11.

Kozlovskyi S.V. (2010), "Strategic analysis of the development of regional economic systems", Efektivna economika, avaible at: http://www.economy.nayka.com.ua/?op=1\&z=178 (Accessed 01.04.2020)

Koziuk V., Hayda Y., Dluhopolskyi O., Kozlovskyi S. (2020), "Ecological performance: ethnic fragmentation versus governance quality and sustainable development", Problemy ekorozwoju Problems of sustainable development, vol. 15(1), pp. 53-64.

Novickyi V. (2004), "Informational interpretation of classical approaches in economic science". Economy of Ukraine, vol. 4, pp. 63.

G. Obikhod, Ecologicalization of economic development as a factor of production modernization / G. Obikhod, A. Omelchenko, T. Nechitaylo // Economist. - K.: Search-Invest WFP, 2016. - № 6. P. 24-27.

Polterovich V. (2008), "Modernization strategies, institutions and coalition", Economic issues, vol. 4, pp. 424.

Rent principles of modernization of the water management complex of Ukraine: [monograph] / [for the total. ed. Acad. National Academy of Sciences of Ukraine, prof. M.A. Khvesik,]. - K .: State University of IPSR of NAS of Ukraine, 2016. - 238 p.

Fedulova L.I. (2006), Tehnologichiy rozvitok Ukraini [Technological development of the Ukrainian economy]. Kyiv, Ukraine.

Fedulova L.I., Alexandrova V.P., Bazhal Y.M., Danko M.S., Kuznetsova I.S. (2005), Innovaciyniy rozvitok economiki: model, systema ypravlinnia, derjavna polituka [Innovative economic development: model, system of government, state policy], Osnjva. Kyiv, Ukraine.

Tsyba G.E. (2004), "Adjusting the development of the national economy to the current conditions of globalization", Actual problems of the economy, vol.4, pp. 30-38. 